Suryani et al., 2020

Volume 6 Issue 2, pp. 54-73

Date of Publication: 25 th August, 2020

DOI- https://doi.org/10.20319/mijst.2020.62.5473

This paper can be cited as: Suryani, E., Hendrawan, R. A., Syafa'at, F. E Az-zahra, A. (2020). Scenario Model to Reduce Traffic Congestion using Intelligent Transportation Systems. MATTER: International Journal of Science and Technology, 6(2), 54-73.

This work is licensed under the Creative Commons Attribution-NonCommercial 4.0 International License. To view a copy of this license, visit http://creativecommons.org/licenses/by-nc/4.0/ or send a letter to Creative Commons, PO Box 1866, Mountain View, CA 94042, USA.

\title{
SCENARIO MODEL TO REDUCE TRAFFIC CONGESTION USING INTELLIGENT TRANSPORTATION SYSTEMS
}

\author{
Erma Suryani \\ Information Systems, Institut Teknologi Sepuluh Nopember(ITS), Surabaya, Indonesia \\ erma.suryani@gmail.com \\ Rully Agus Hendrawan \\ Information Systems, Institut Teknologi Sepuluh Nopember(ITS), Surabaya, Indonesia \\ ruhendrawan@gmail.com \\ Fizar Syafa'at \\ Information Systems, Institut Teknologi Sepuluh Nopember(ITS), Surabaya, Indonesia \\ fizar.inf@gmail.com

\begin{abstract}
Alifia Az-Zahra
Civil Engineering, Institut Teknologi Sepuluh Nopember (ITS), Surabaya, Indonesia alifia9697@gmail.com
\end{abstract}

\begin{abstract}
This study aims to develop scenario model to reduce traffic congestion using intelligent transportation systems (ITS). ITS is an application of advanced technology in the fields of electronics, computers and telecommunications to make transportation infrastructure and facilities more informative, smooth, safe and comfortable. It encompasses the latest wireless, electronic, simulation, and automatic technology. As a method to develop the scenario model, system dynamics (SD) is utilized considering that it can accommodate a system with complex non-linearity, faster and easier sensitivity analyses through the tests on the structure of the models. SD has been used at
\end{abstract}


the macroscopic and microscopic levels of the traffic flow to explore the interaction of transportation and urban planning as well as to evaluate the effect of different transport policies. ITS can reduce traffic congestion through the placement of several surveillance cameras in some corners of the city and is equipped with sensors to detect the number of vehicles. This detection results can be used as an input in setting the time for traffic signal control to reduce the volume of vehicles by prioritizing solid lines to get the green light so that the flow of heavy traffic can run first. With this scenario, traffic congestion is projected to decrease to be in the range $0.71-0.79$ (below the maximum saturation level of 0.85 ) due to the decrease in vehicle volume as the impact of the implementation of ITS.

\section{Keywords}

Model, Simulation, Intelligent Transportation Systems, System Dynamics, Traffic Congestion

\section{Introduction}

Transportation is a major component in everyday life and the social system. In urban areas, there is a trend of a high increase in population due to birth rates and urbanization. Traffic congestion occurs when traffic conditions on a highway are unstable and the speed of operation decreases rapidly (Sumadi, 2006). Intelligent Transportation System (ITS) is the application of advanced technology in the fields of electronics, computers, and telecommunications to make transportation infrastructure and facilities more informative, smooth, safe, and comfortable as well as environmentally friendly. ITS can retrieve traffic data through sensors and video cameras installed on roads and bridges (Cheng, Pang, \& Pavlou, 2019). ITS can be a solution in dealing with traffic congestion, reducing traffic accidents, and mitigating environmental externalities caused by road transportation (United Nation, 2017).

Intelligent Transportation Systems use accurate knowledge of traffic conditions and the level of road safety to improve user safety and overcome traffic congestion (Souza, Pedrosa, Botega, \& Villas, 2018). Intelligent Transportation Systems have been developed for more sophisticated traffic demand management and the selection of effective and reliable congestion mitigation strategies (Sun et al., 2019). Therefore, this research developed a scenario model to reduce traffic congestion using intelligent transportation systems (ITS). ITS can overcome congestion by placing surveillance cameras and is equipped with sensors to detect the number of vehicles. These detection results can 
be used as input in regulating and manipulating the time of the traffic lights so that the flow of heavy traffic can run first.

\subsection{Intelligent Transportation System (ITS)}

ITS is an integrated technology that includes electronics, information processing, wireless communication, and control which aims to improve safety, efficiency, and comfort (Shaheen \& Finson, 2017). ITS can detect the flow of traffic collected from sensors and video cameras installed on roads. ITS can facilitate the road traffic control system and carry out traffic monitoring (Jarasuniene \& Batarliene, 2013). ITS also facilitates the management of transportation flows by reducing congestion and ensuring the safety and comfort of the driver (Chowdhury \& Sadek, 2003). ITS aims to solve road traffic problems such as traffic congestion by connecting people, roads, and vehicles in information and communication networks as seen in Figure 1 (Japan Society of Civil Engineers, 2016).

Human

Communication

Technologies

\begin{tabular}{|c|}
\hline Road \\
\hline Sensory info technology \\
\hline Positioning technology \\
\hline$\quad$ Mapping info technology \\
\hline$\quad$ Info communication technology \\
\hline$\quad$ Info network technology \\
\hline
\end{tabular}

Figure 1: ITS Components

\section{Literature Review}

This section presents a literature review consisting of intelligent transportation systems and the role of system dynamics in reducing traffic congestion using ITS. 


\subsection{The role of system dynamics in reducing traffic congestion}

System dynamics is a discipline based on the theory of nonlinear dynamics and feedback control. The system dynamics simulation model of traffic congestion is required due to the dynamic complexity of the real system. The application of the system dynamics simulation model in the field of transportation systems has been explored in some literature (Barlas, 2002; Springael, Kunsch, \& Brans, 2002; Wegener, 2004). System dynamics is a method to learn about system behavior in complex systems (J. D. Sterman, 2000).

Swanson (2000) has developed a dynamic urban model to simulate interactions between transportation, land use, population, and economic activity in urban areas. Yao \& Chen (2015) have developed a dynamics model system for urban sustainable transportation planning. (Frances Agyapong \& Ojo, 2018) have developed a system dynamics model for managing traffic congestion. To develop a system dynamics model, several steps are required (John D. Sterman, 2002), namely: 1) problem formulation; 2) dynamic hypothesis; 3) simulation model development; 4) model validation; and 5) scenario development

\section{Base Model Development}

This section presents base model development consisting of problem formulation, causal loop diagram development, as well as stock and flow diagram development.

\subsection{Problem Formulation}

This step includes the determination of the model boundaries and variables to ensure that the model variables are aligned with the modelling goal. We determined the endogenous and exogenous variables based on previous researches as seen in Table 1.

Table 1: Mapping between the Model Objective with the Endogenous and Exogenous Variables

\begin{tabular}{|l|l|l|}
\hline \multicolumn{1}{|c|}{ Modelling Objective } & \multicolumn{1}{|c|}{ Endogenous variable } & \multicolumn{1}{|c|}{ Exogenous variable } \\
\hline $\begin{array}{l}\text { Reducing traffic } \\
\text { congestion }\end{array}$ & $\begin{array}{l}\text { Population } \\
\text { (Ismiyanti, D., \& D., 2012) }\end{array}$ & $\begin{array}{l}\text { Road Capacity } \\
\text { (Ismiyanti et al., 2012) }\end{array}$ \\
\cline { 2 - 3 } & $\begin{array}{l}\text { Daily Traffic Volume } \\
\text { (Harahap, Suryadi, Ridwan, Darmawan, \& Ceha, } \\
\text { 2017) } \\
\text { (Ismiyanti et al., 2012) }\end{array}$ & \\
\cline { 2 - 3 } & $\begin{array}{l}\text { Intelligent Transportation Systems } \\
\text { (Desertot, Lecomte, Gransart, \& Delot, 2013) }\end{array}$ & \\
\hline
\end{tabular}




\subsection{Causal Loop Diagram (CLD) Development}

A CLD is a qualitative method for demonstrating the interrelationships of variables in a system. Traffic congestion depends on the average daily traffic, road capacity, traffic monitoring using an intelligent transportation system (ITS) (Desertot et al., 2013; Harahap et al., 2017; Ismiyanti et al., 2012) as seen in Figure 2.

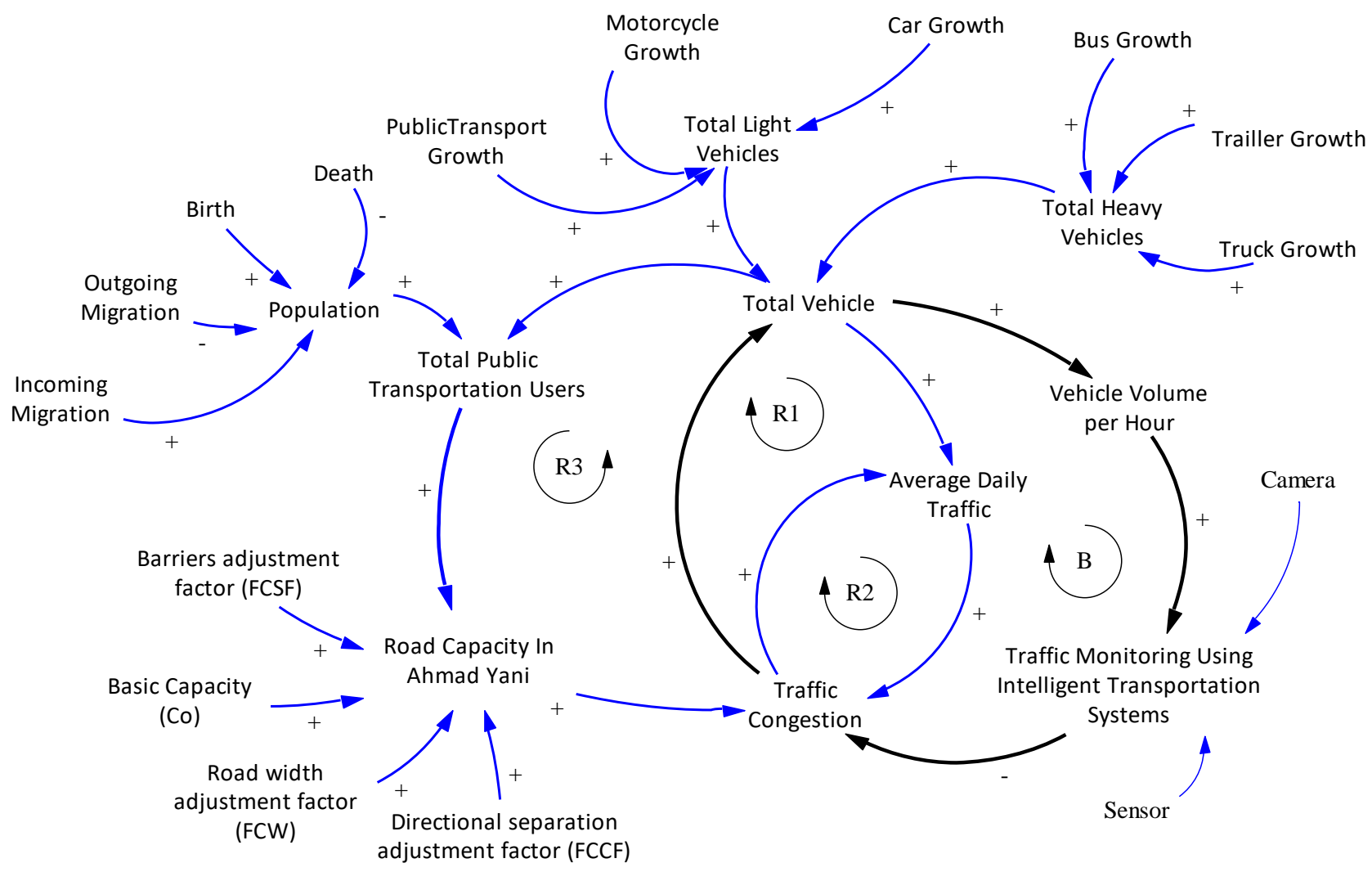

Figure 2: $C L D$ of Traffic Congestion

CLD describes the behavior of a system by presenting feedback loops such as reinforcing and balancing loops. Reinforcing feedback loops (R) indicate that changes in a node are in the same direction, whereas the balancing feedback loop (B) represents a change in the opposite direction. Road capacity depends on the basic capacity, barriers adjustment, road width adjustment, and directional separation adjustment factors. The total vehicle affects vehicle volume per hour. The implementation of ITS is expected to reduce traffic congestion by regulating and manipulating the time of the traffic to reduce congestion.

\subsection{Stock and Flow Diagram (SFD) Development}

SFD consists of symbols and specific components that represent the structure of the system. 


\subsubsection{SFD of Population}

The population depends on the birth and death rates as seen in Figure 3. Incoming migration and the number of births can increase the population. Meanwhile, the outcoming migration and the number of deaths decrease the number of population.

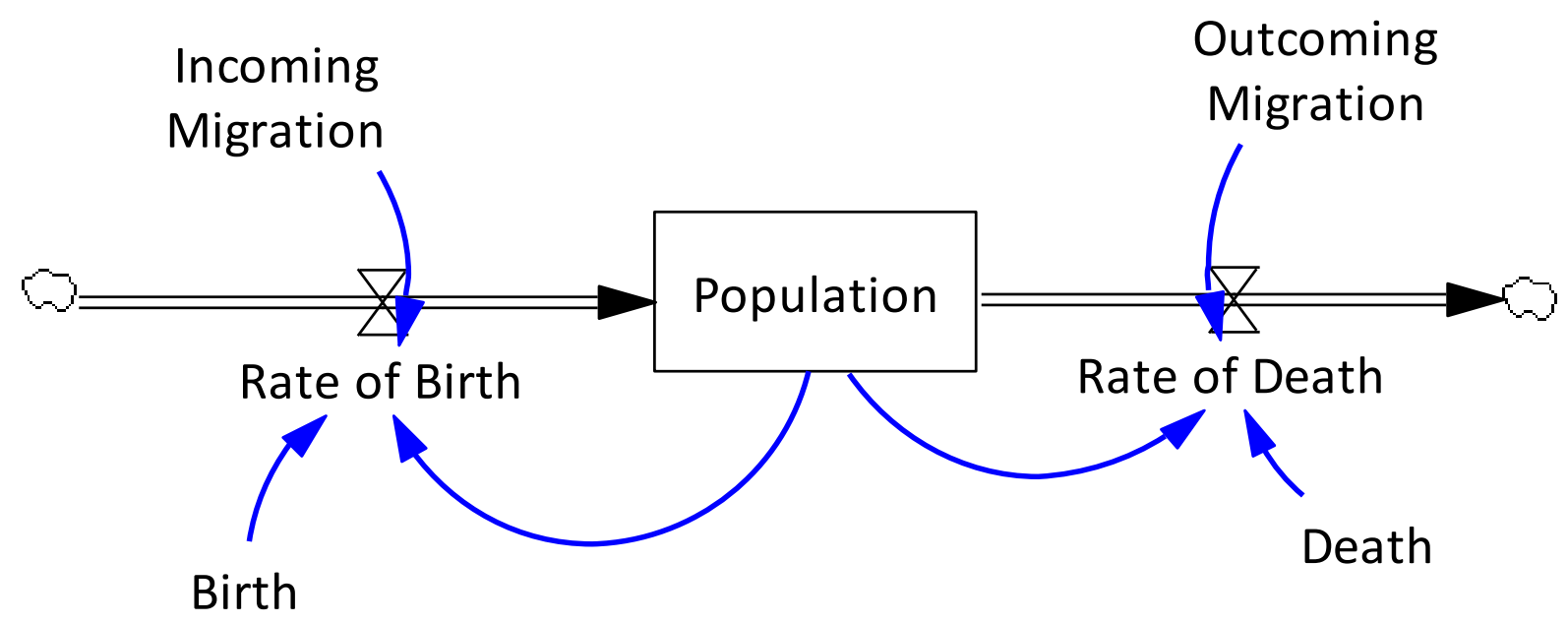

Figure 3: SFD of Population

The model formulation of the population can be seen in Eq. (1):

$$
\mathrm{P}(\mathrm{t}+1)=P\left(t_{0}\right)+\int B(t)-D(t)
$$

where:

$$
\begin{array}{ll}
\mathrm{P} & =\text { Population } \\
\mathrm{B} & =\text { Birth Rate } \\
\mathrm{D} & =\text { Death Rate }
\end{array}
$$

\subsubsection{SFD of Total Vehicle}

The total vehicle is the summation of total light vehicle and total heavy vehicle as seen in Figure 4. As we can see from Figure 4, total light vehicle is influenced by the number of motorcycles, cars, and public transportation (Lyn). Meanwhile, the total of heavy vehicle depends on the number of trailers, buses, and trucks. 


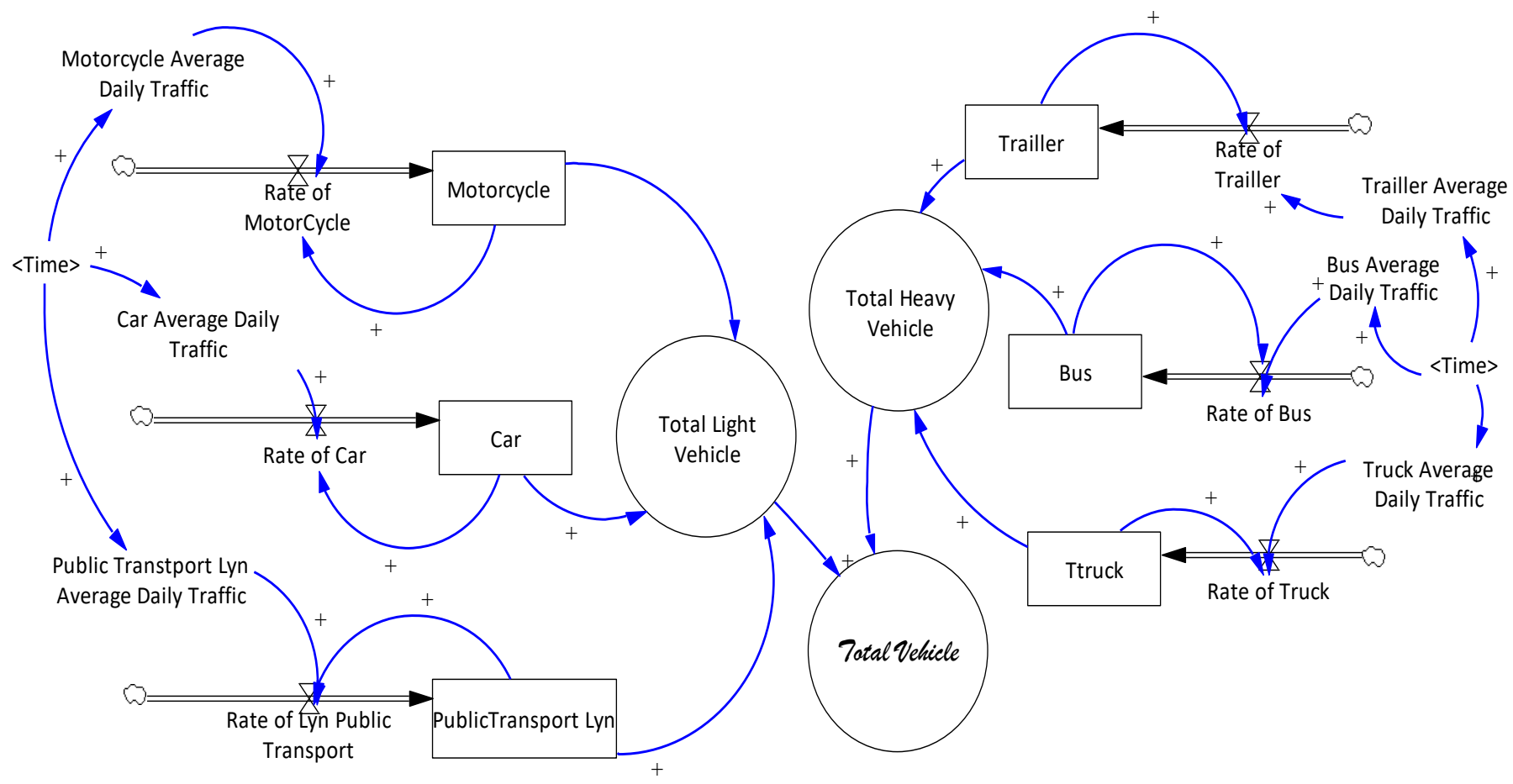

Figure 4: SFD of Total Vehicle

\subsubsection{SFD of the Percentage of Public Transport (PT) Users}

The percentage of PT users depends on the number of population and the number of people who use PT as seen in Figure 5.

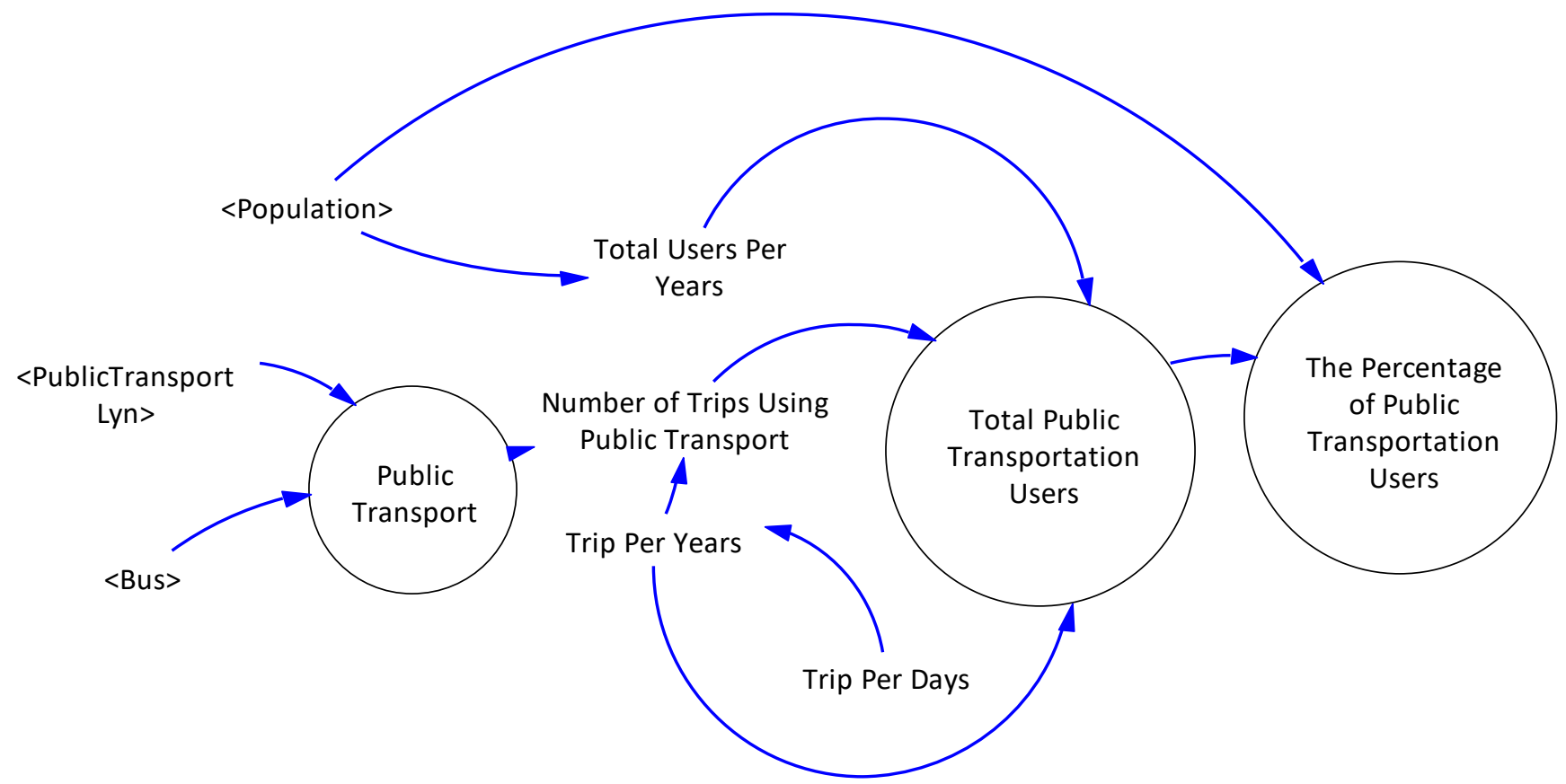

Figure 5: SFD of the Percentage of Public Transport Users 
Model formulation of the percentage of PT users can be seen in Eq. 2.

$$
\mathrm{PPT}=(\mathrm{TPTU} / \mathrm{P}) * 100(2)
$$

where:

PPT $=$ The Percentage of PT Users

TPTU $=$ Total PT Users

$\mathrm{P} \quad=$ Population

\subsubsection{SFD of Traffic Monitoring Using ITS}

SFD of traffic monitoring using ITS can be seen in Figure 6.

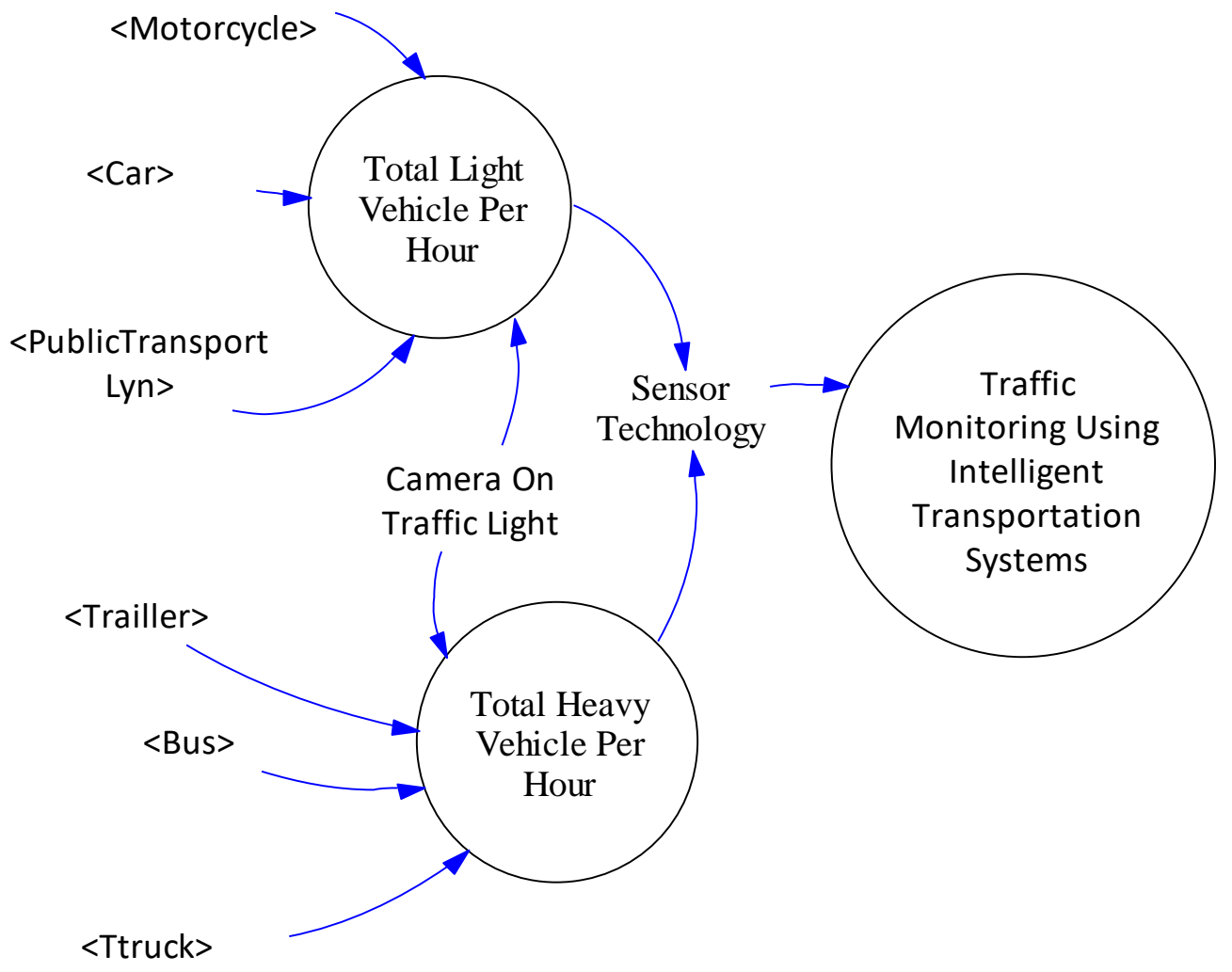

Figure 6: SFD of Traffic Monitoring Using Intelligent Transportation Systems

Traffic cameras will detect the incoming vehicles; while, sensor technology is used to collect data on the number of vehicles.

\subsubsection{SFD of Traffic Congestion}

Traffic congestion is influenced by hourly traffic volume and road capacity as seen in Figure 7. Some factors such as basic capacity, barrier adjustment, road width adjustment, and directional separation adjustment are important factors that influence the road capacity. The model formulation for traffic congestion can be seen in Eq. (3). 
where:

$\mathrm{TC}=$ Traffic Congestion

HTV = Hourly Traffic Volume

$\mathrm{RC} \quad=$ Road Capacity

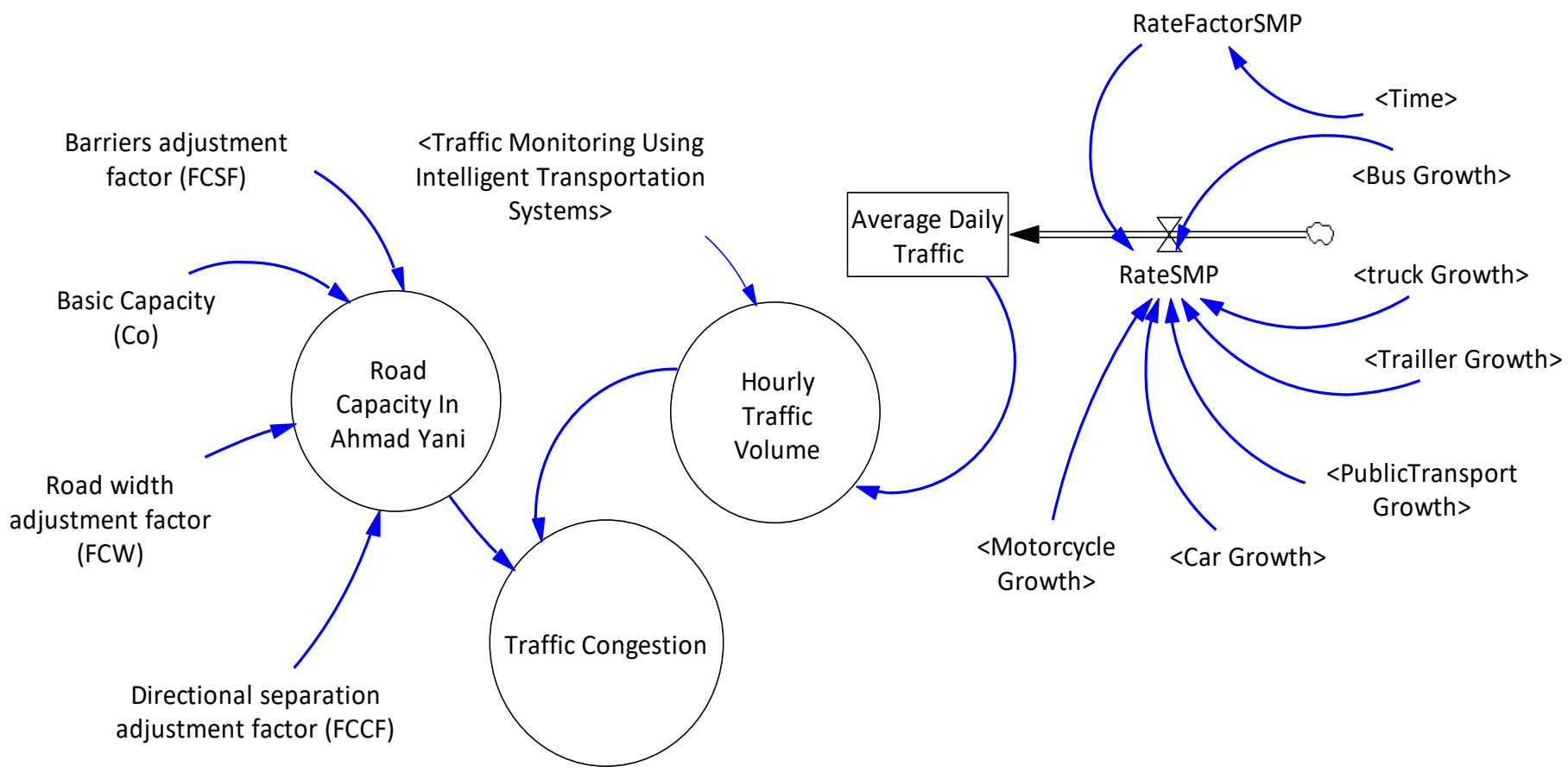

Figure 7: SFD of Traffic Congestion

\section{Model Validation}

Model validation is required to check the model validity. This time frame is considered based on the availability of data and the behavior of the system. The model is valid if the error rate is $\leq 5 \%$ and the error variance is $\leq 30 \%$ (Barlas, 2002). The model is validated by checking the error rate and error variance as shown in Equation (4) - (5).

$$
\begin{aligned}
& \mathrm{A}=\frac{\lceil\overline{\mathrm{S}}-\overline{\mathrm{A}}\rceil}{\overline{\mathrm{A}}} \\
& \mathrm{S}=\frac{\lceil\mathrm{Ss}-\mathrm{Sa}\rceil}{\mathrm{Sa}}
\end{aligned}
$$

where:

$\bar{S}=$ average rate of simulation

$\bar{A}=$ average rate of data

$\mathrm{A}=$ data at time $\mathrm{t}$ 
$\mathrm{S}=$ simulation result at time $\mathrm{t}$

$S_{S}=$ standard deviation of simulation

$S_{a}=$ standard deviation of data

The error rates of average daily traffic (ADT) of Lyn PT, private car, and bus were:

Error rate of 'ADT of Lyn PT' $=\frac{[4414-4241]}{4241}=0.041$

Error rate of 'ADT of private car' $=\frac{[64343-62134]}{62134}=0.036$

Error rate of 'ADT of' bus' $=\frac{[830-802]}{802}=0.035$

The error variances of ADT of Lyn public transport, private car, and bus were:

Error variance of 'ADT of Lyn public transport' $=\frac{[2681-2677]}{2677}=0.145$

Error variance of 'ADT of private car' $=\frac{[19490-16406]}{16406}=0.154$

Error variance of 'ADT of bus' $=\frac{[322-340]}{340}=0.054$

A comparison between the simulation results and the historical data of ADT of Lyn PT, private car, and bus in Ahmad Yani street can be seen in Figs. 8-10.

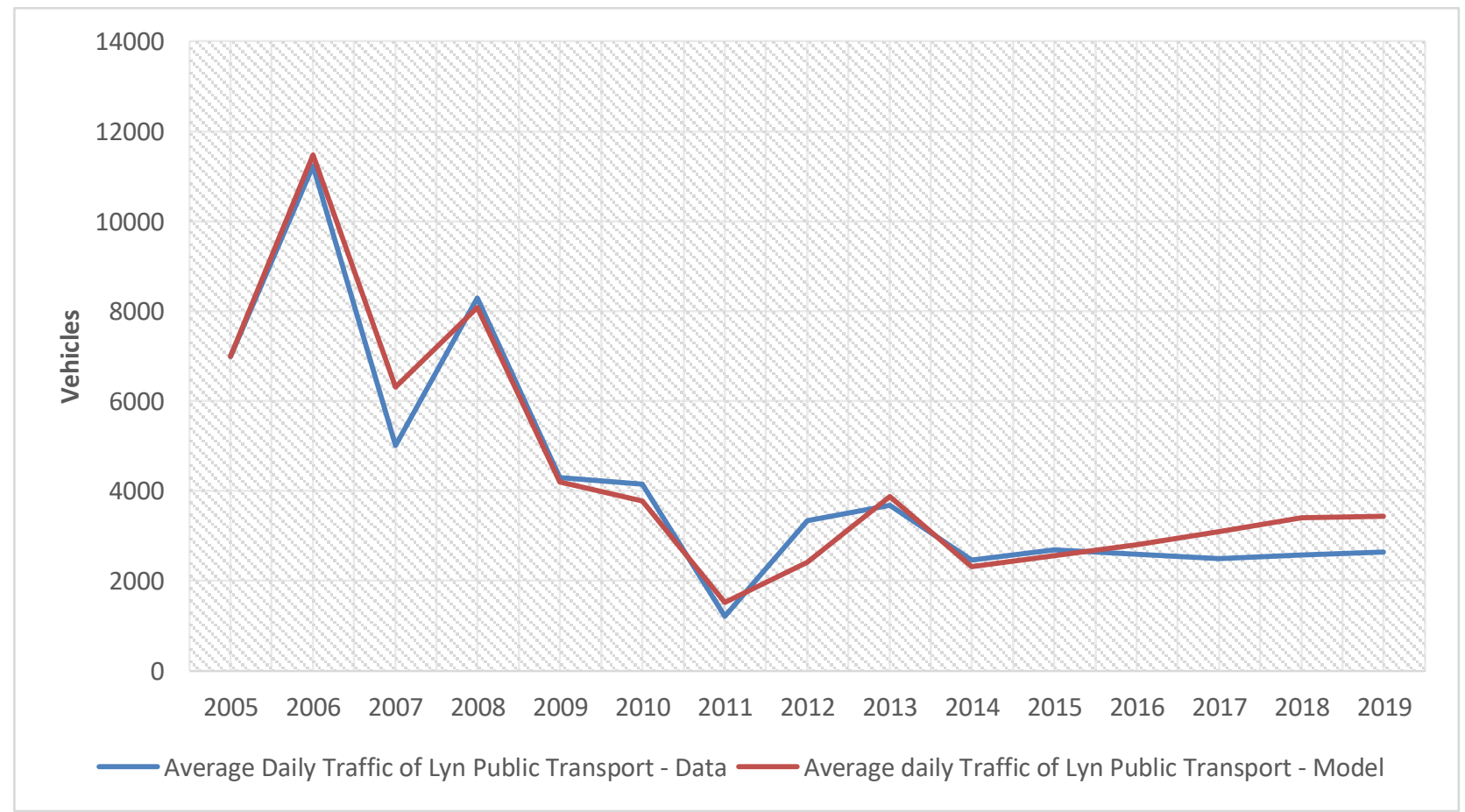

Figure 8: A Comparison Between Model and Data of the ADT of Lyn PT 


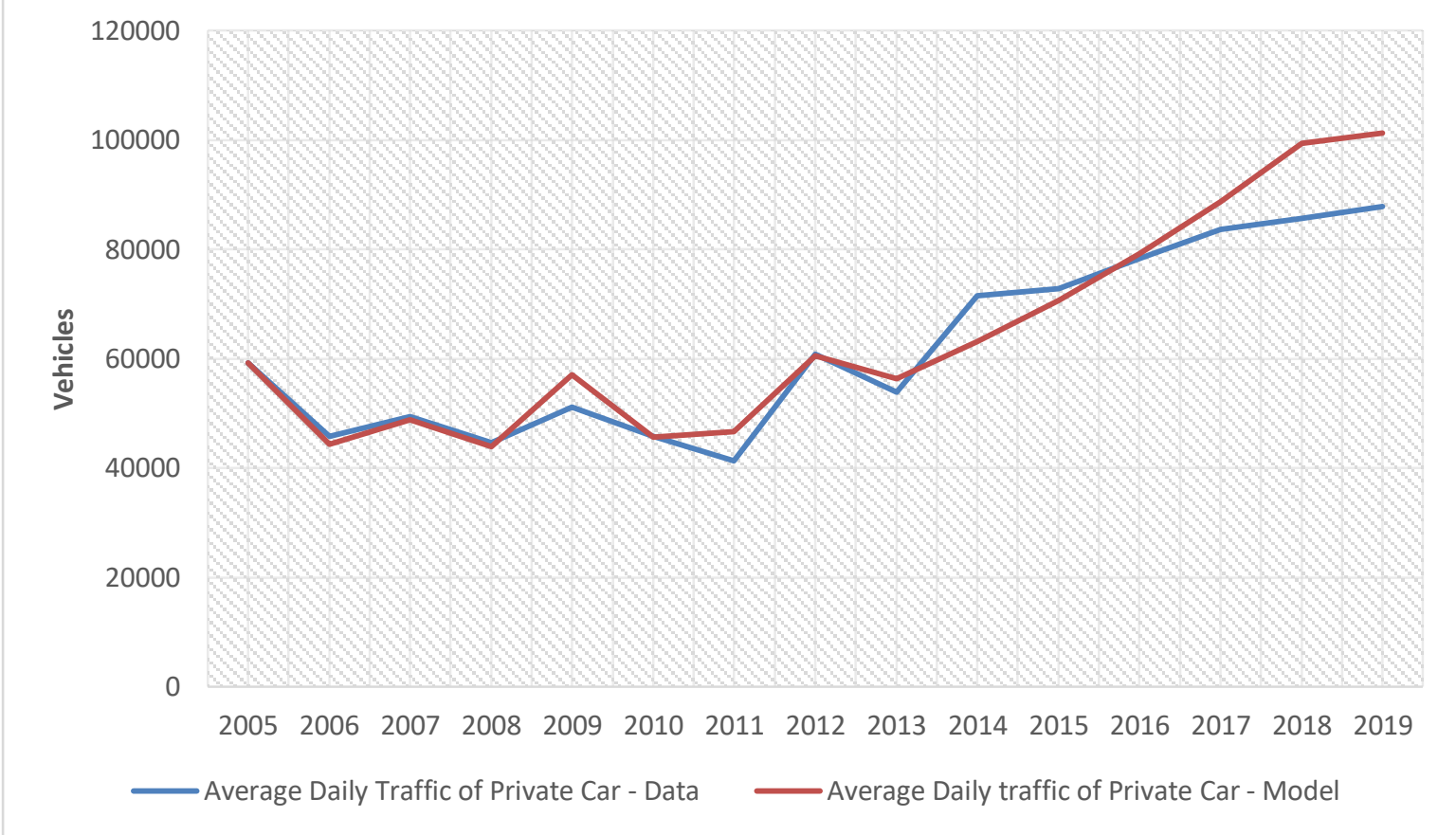

Figure 9: A Comparison Between Model and Data of the ADT of Private Car

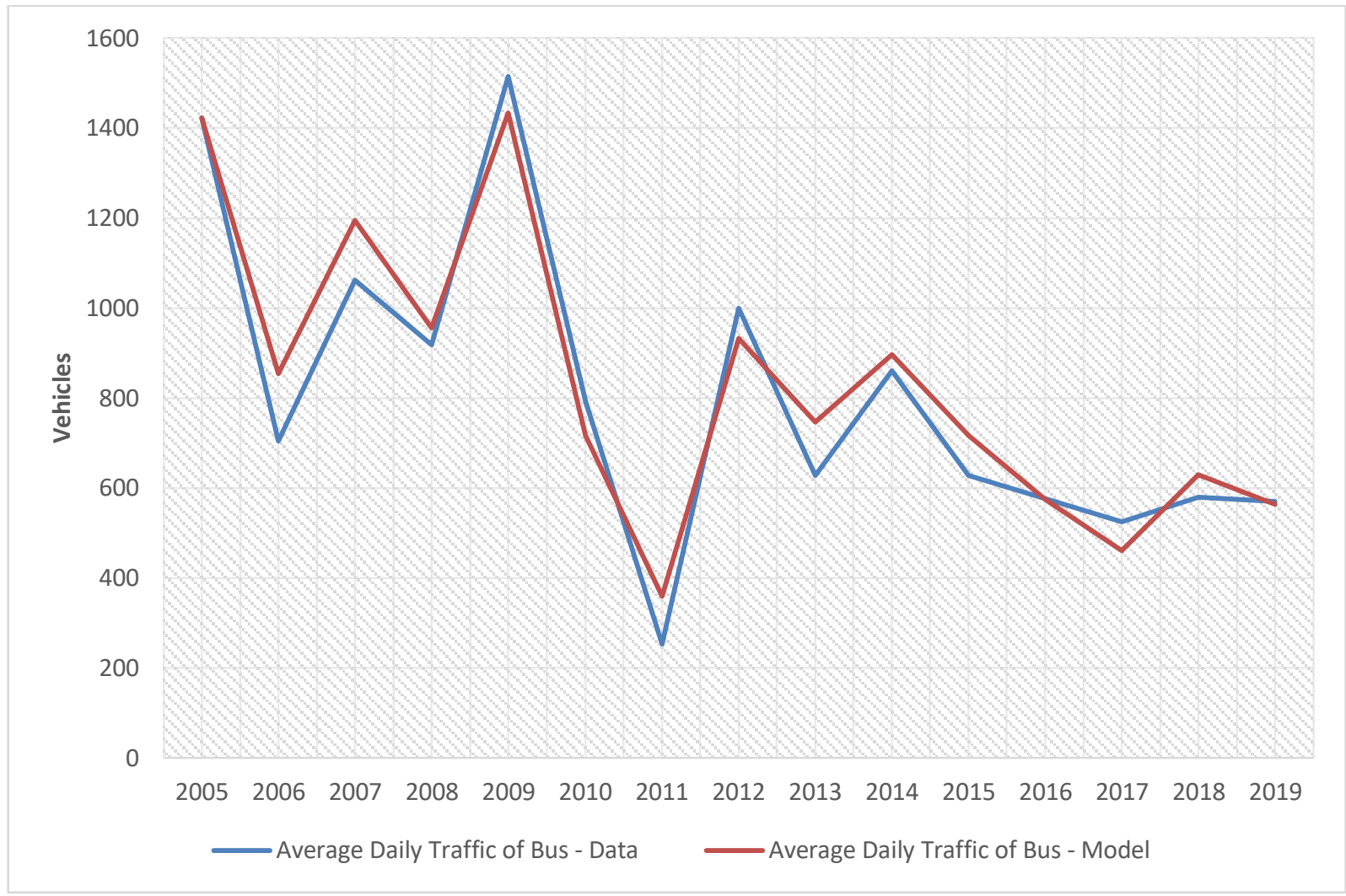

Figure 10: A Comparison Between Model and Data of the ADT of Bus 


\section{Results and Discussion}

This section demonstrates the simulation results of several submodels such as population, total vehicle, the percentage of public transport users, traffic monitoring using ITS, and traffic congestion. All data and information in this study were obtained from the city of Surabaya, East Java, Indonesia. We have developed the model as generic as possible so that it can be implemented for other regions by changing the parameter values of the model in accordance with the case study".

\subsection{Population Submodel}

The results of the population simulation can be seen in Figure 11. The population in Surabaya city has increased every year with an average growth of $1.3 \%$ per year. Therefore, in 2019, it will reach around 3.34 million people.

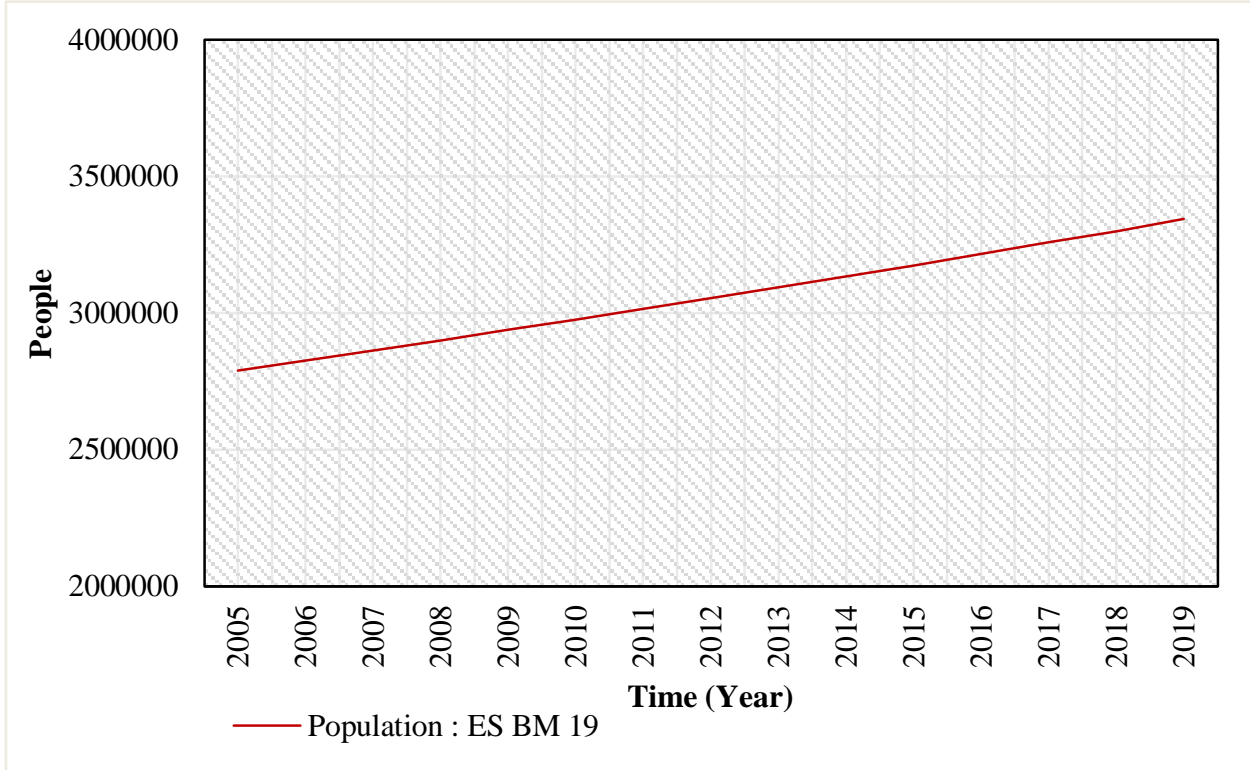

Figure 11: Population in Surabaya City

\subsection{Total Vehicle Submodel}

The simulation result of the total vehicle in Surabaya city can be seen in Figure 12. Total vehicles in Surabaya from 2005-2018 continued to increase with an average growth of 7\% per year. In 2019 , total vehicles have decreased by $18.4 \%$ due to the decreasing number of motorcycles. 


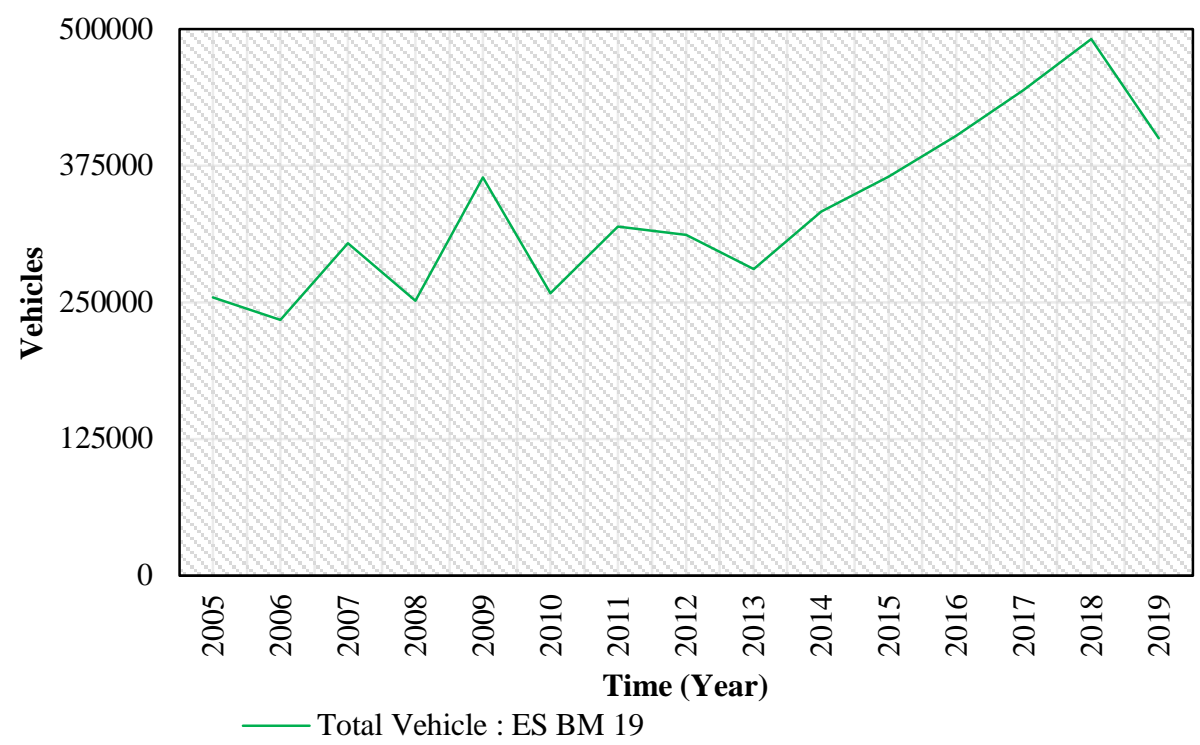

Figure 12: Total Vehicle in Surabaya City

\subsection{The Percentage of Public Transport (PT) Users Submodel}

The simulation result of the total vehicle in Surabaya city can be seen in Figure 13. The results of simulation show that the percentage of PT users in the period of 2006 to 2011 tended to decrease, remaining $1.5 \%$ in 2011. The highest percentage occurred in 2006 at around 9.9\%. In 2019, the percentage of public transport users was around 3.2\%, due to the increasing number of population which was not in line with the increasing use of public transport.

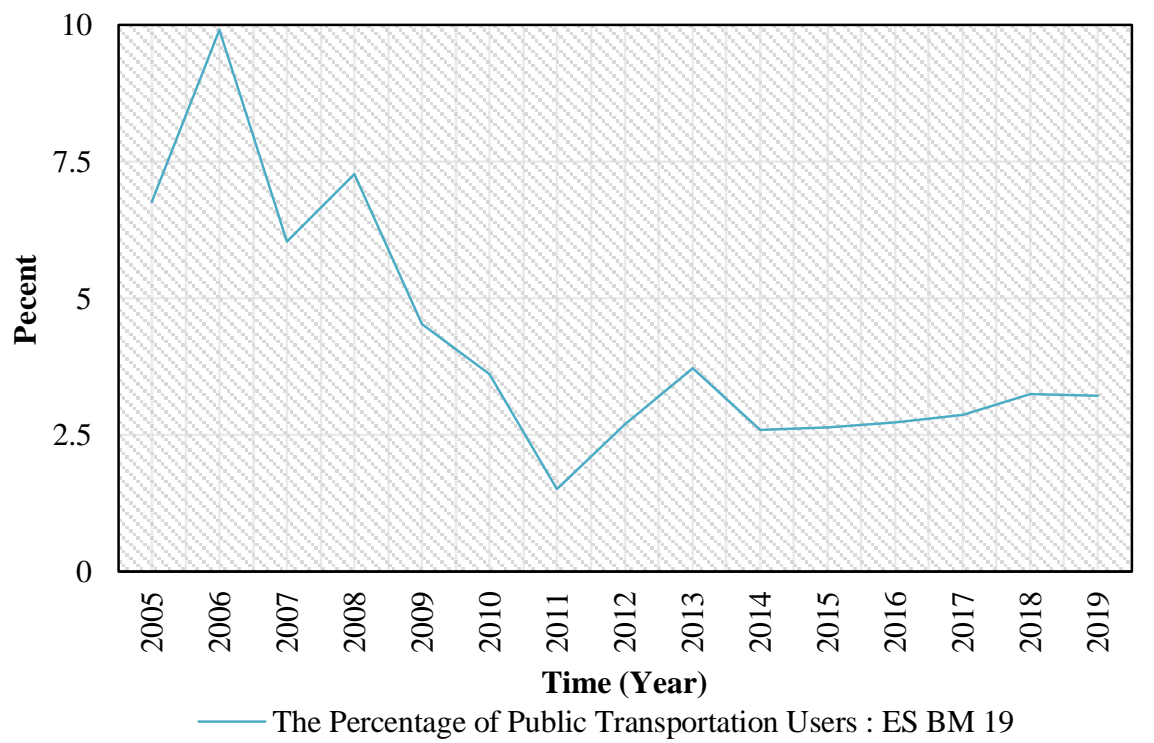

Figure 13: The Percentage of Public Transport Users 


\subsection{Traffic Monitoring Using ITS Submodel}

The results of the simulation on the number of vehicles detected by traffic monitoring can be seen in Figure 14. Here, the average number of vehicles per hour increased with a growth of $7 \%$ per year, so that it reached 20.452 vehicles per hour in 2018. However, this number decreased in 2019, i.e. to 16.686 vehicles per hour, due to the decreasing number of motorcycles.

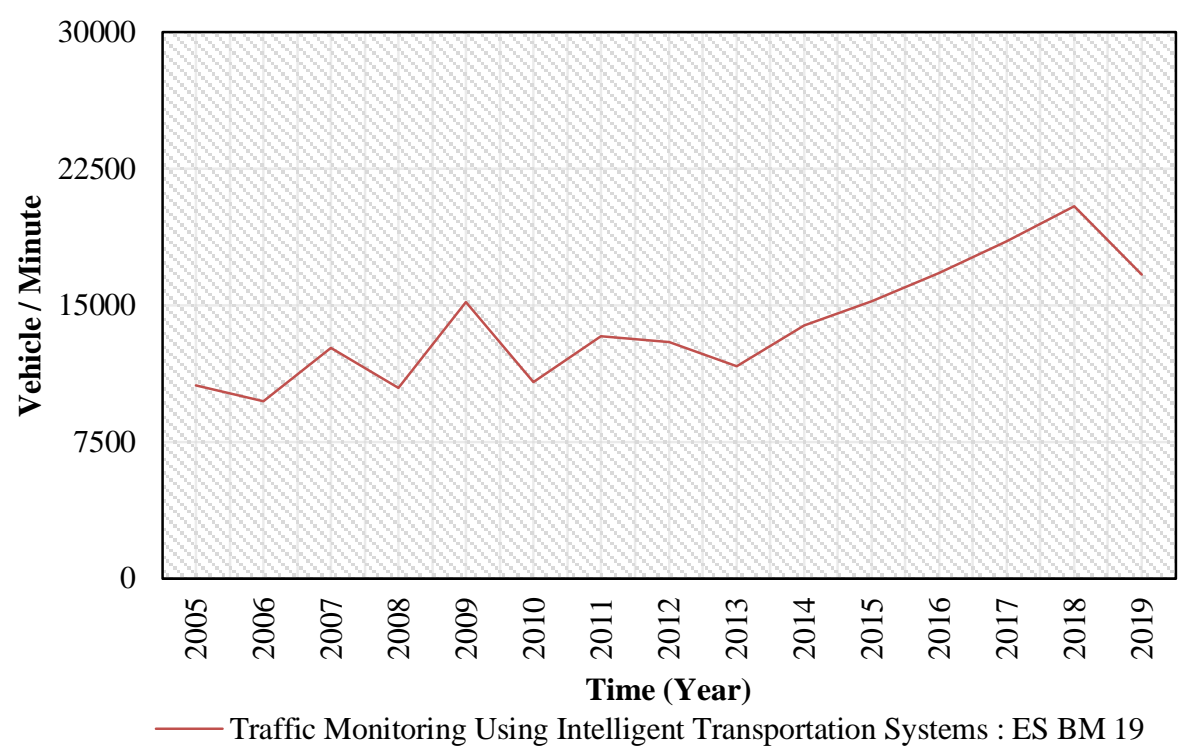

Figure 14: The Number of Vehicles Detected by Traffic Monitoring

\subsection{Traffic Congestion Submodel}

The results of the simulation on traffic congestion can be seen in Figure 15. Traffic congestion exceeded 0.85 (Dmnl = Dimension Less) in 2005, 2009, 2012, 2014-2019. Hale \& Courage (2002) stated that the maximum saturation level of traffic congestion was $85 \%$, therefore, it needed a strategy to reduce traffic congestion. 


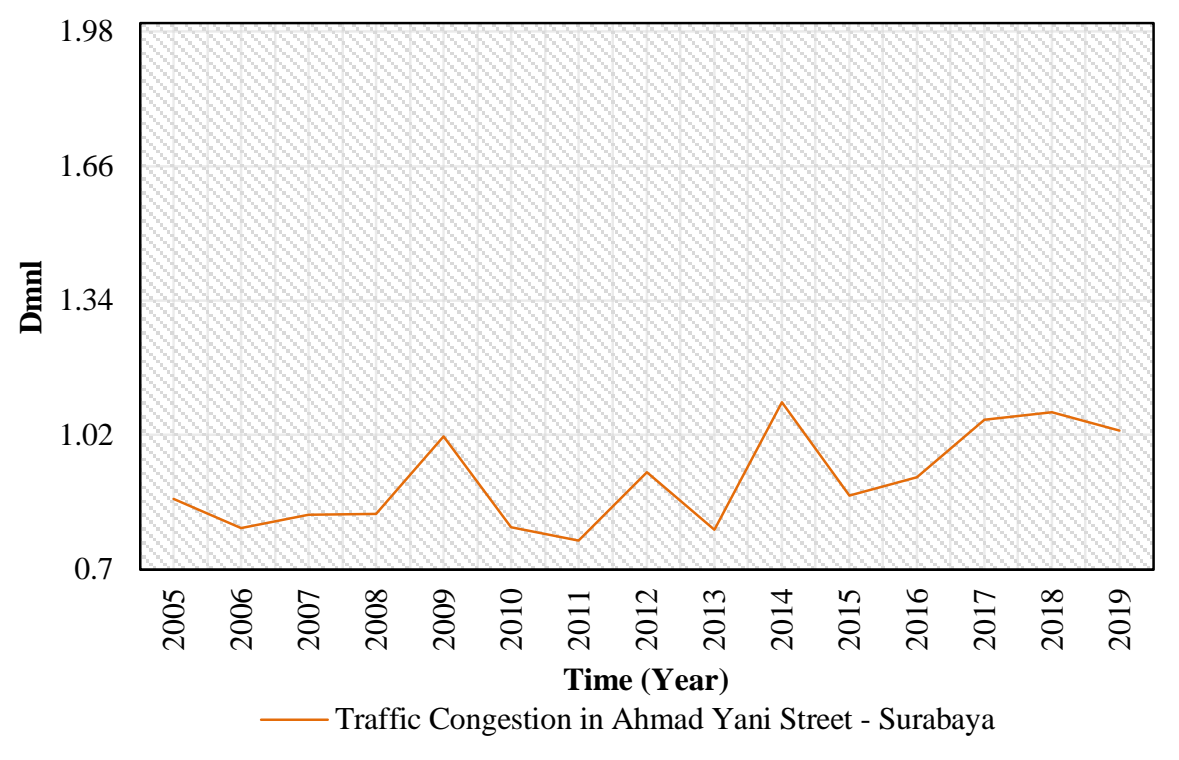

Figure 15: Traffic Congestion in Ahmad Yani Street - Surabaya

\section{Scenario Model Development}

This section presents a scenario model development to reduce traffic congestion. Scenario development is a method of strategic planning that can analyze projections for the interpretation of future conditions (Brose, Fügenschuh, Gausemeier, Vierhaus, \& Seliger, 2013). Scenario development can be conducted by modifying the model's structure and parameters (Suryani, 2011). The scenario model of reducing traffic congestion using traffic monitoring and control system can be seen in Figures 16-17. By using traffic monitoring and control, the number of vehicles passing the highway can be detected by sensors. Vehicle data are then delivered to the server of ITS and can be used as input for traffic signal control. The control method used is a dynamic control method that will prioritize dense lanes to get the green light. 


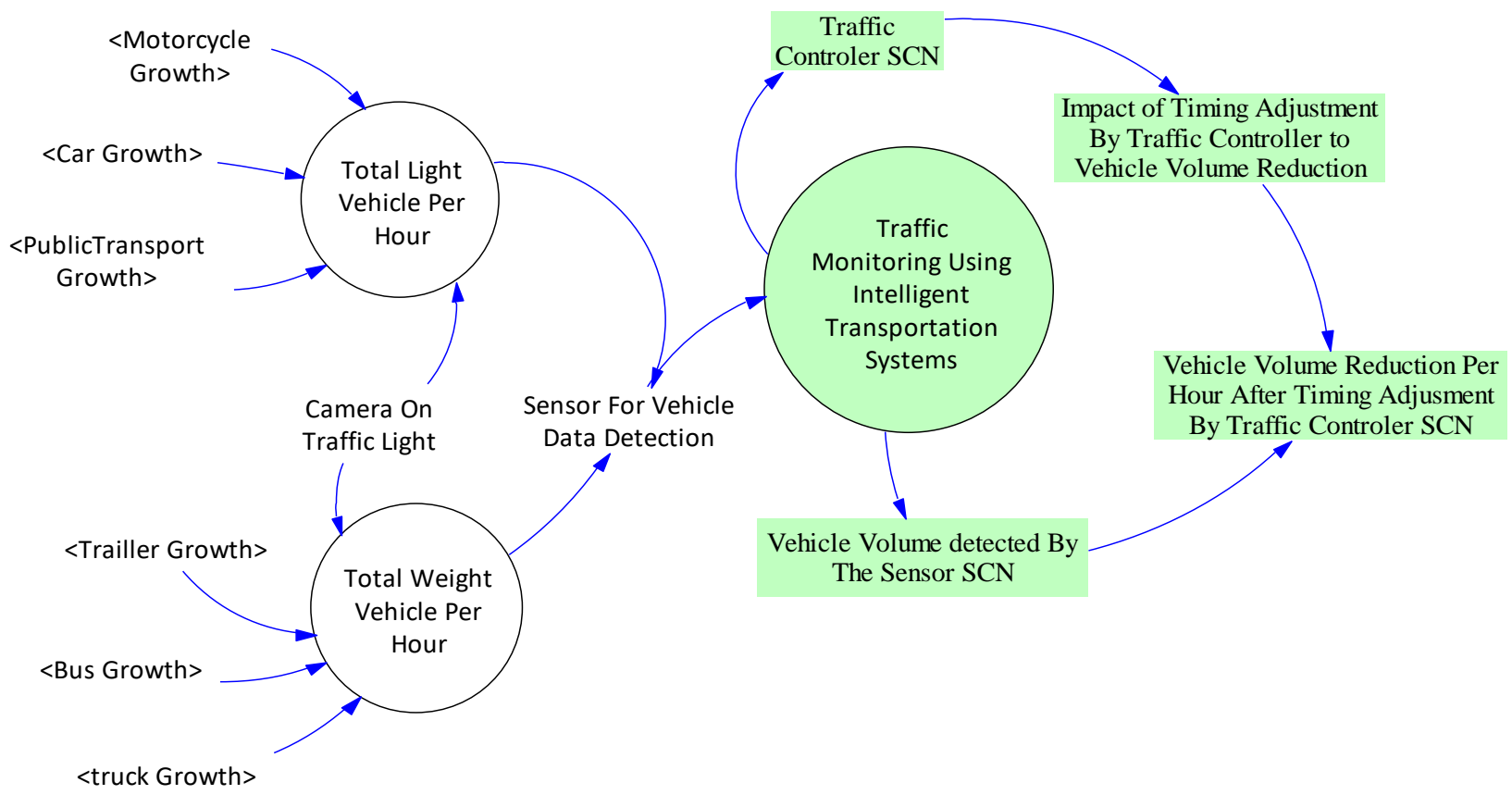

Figure 16: Scenario Model of Vehicle Volume After Timing Setting by Traffic Controller of ITS

This vehicle volume reduction per hour then becomes a feedback variable on the hourly traffic volume as seen in Figure 17.

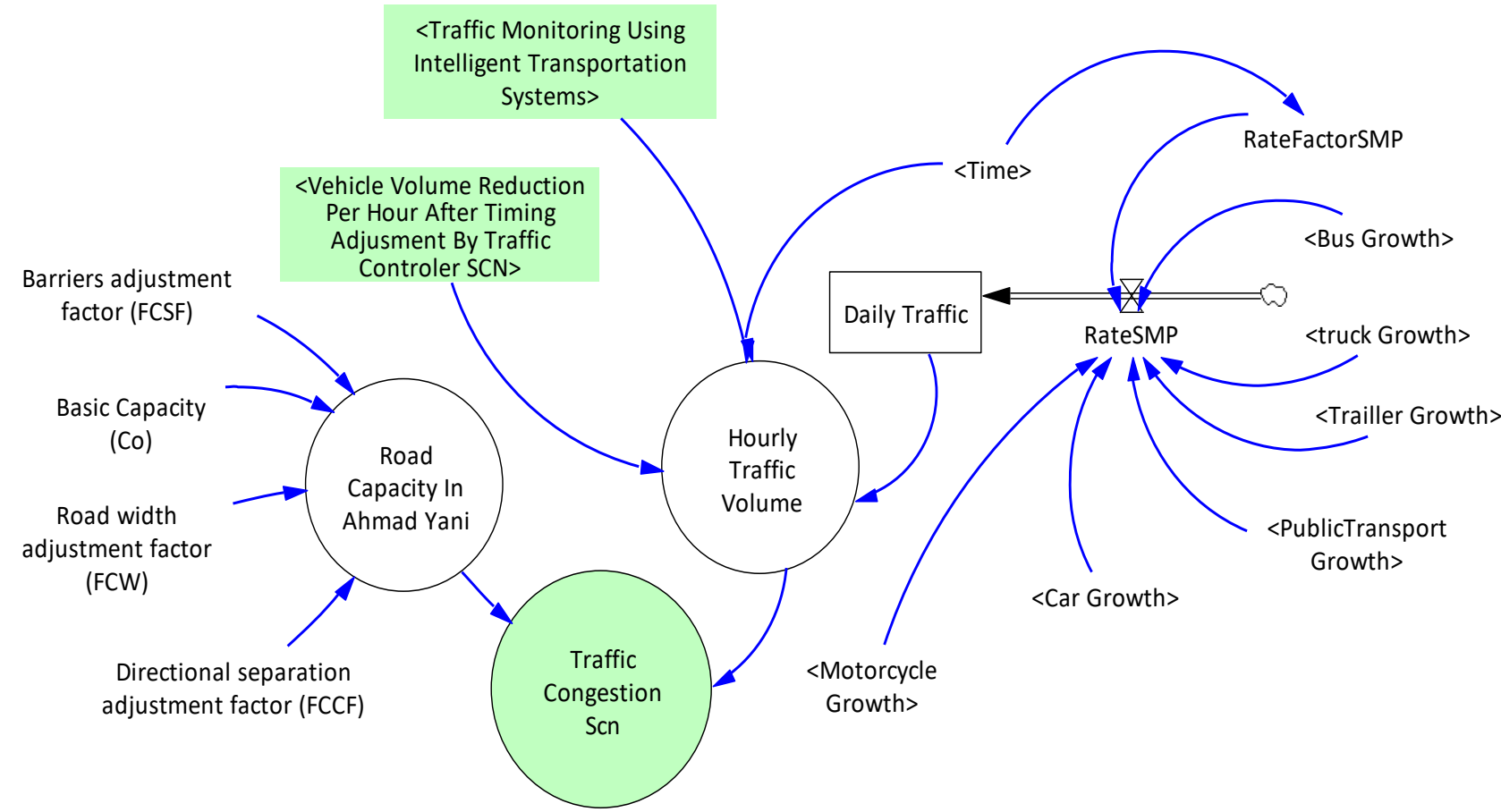

Figure 17: Scenario Model of Traffic Congestion After Scenario 
The results of simulation show that traffic congestion after using traffic monitoring and control can be below the maximum saturation level (0.85). Traffic congestion was projected to be in the range 0.71 - 0.79 as seen in Figure 18, due to the decrease in vehicle volume as the impact of the implementation of ITS which facilitated the traffic monitoring and control system.

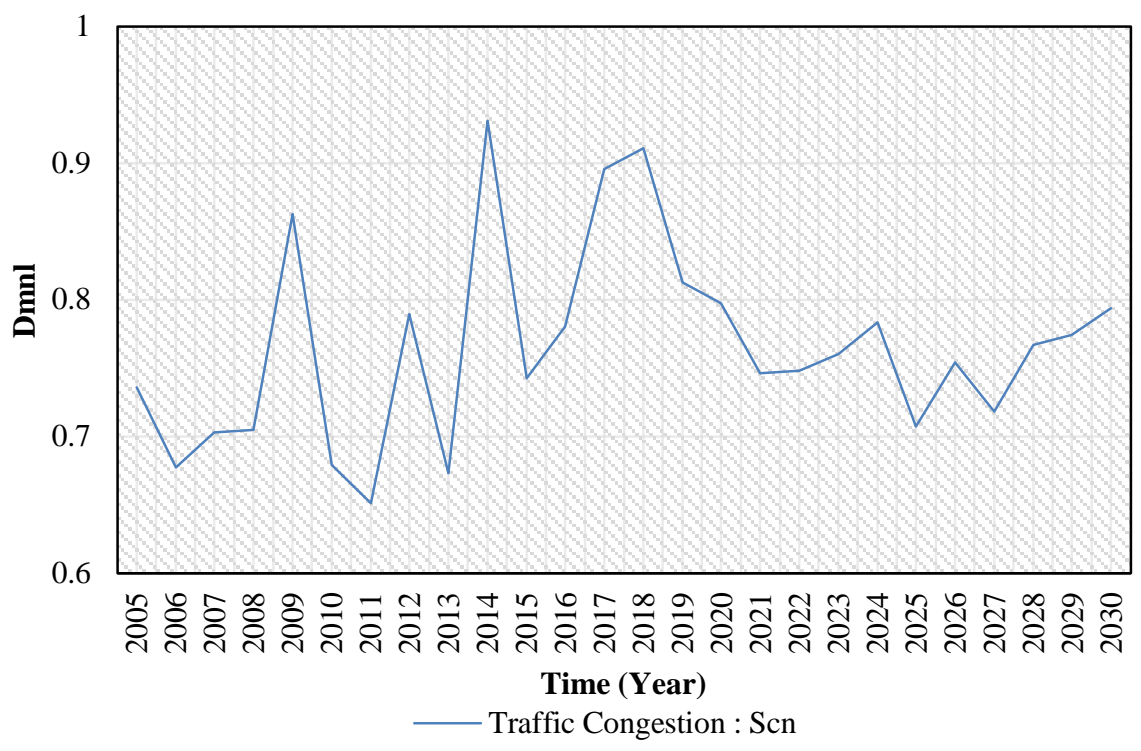

Figure 18: Traffic Congestion after Using Traffic Monitoring and Control

\section{Conclusion and Further Research}

This research was designed to provide a comprehensive and objective assessment of reducing traffic congestion using simulation models and scenarios. To build the simulation models and develop the scenario, system dynamics (SD) was used considering that SD can accommodate the dynamics complexity of traffic congestion. This research was conducted in Surabaya City, Indonesia, which is the fourth most congested city in the world. The novel contributions of this research are, namely: formulating relationships between variables, building the dynamic behavior of traffic congestion as well as developing scenario to reduce traffic congestion using ITS. All data and information in this study were obtained from the city of Surabaya - East Java - Indonesia. Although the data is regional, we have developed the model as generic as possible, so that it can be implemented for other regions by changing the parameter values of the model in accordance with the case study. Some important factors that affect traffic congestion are vehicle volume and road capacity. Road capacity depends on the basic capacity, barriers adjustment, road width adjustment, and directional separation adjustment factors. Total vehicle affects the vehicle volume per hour. The 
implementation of ITS can reduce traffic congestion by regulating and manipulating the time of the traffic. The total vehicle is the summation of total light vehicles and total heavy vehicles. Total vehicles in Surabaya from 2005-2018 continued to increase with an average growth of 7\% per year. The percentage of public transport users in the period of 2006 to 2011 tended to decrease, the remaining $1.5 \%$ in 2011. The highest percentage occurred in 2006 at around 9.9\%. In 2019, the percentage of public transport users was around 3.2\%, due to the increasing number of population which was not in line with the increasing use of public transport. Scenario results show that traffic congestion after using traffic monitoring and control can reduce traffic congestion below the maximum saturation level (0.85). Traffic congestion was projected to be in the range $0.71-0.79$, due to the decrease in vehicle volume as the impact of the implementation of ITS which facilitates the traffic monitoring and control system. Further research is required to develop a sustainable transportation system by considering the transit-oriented development (TOD) program.

\section{Acknowledgment}

This work is supported by ITS (Institut Teknologi Sepuluh Nopember) Research Center, Enterprise Systems Laboratory, City Transportation Office of Surabaya.

\section{REFERENCES}

Barlas, Y. (2002). System Dynamics: Systemic Feedback Modeling for Policy Analysis: Encyclopedia for Life Support Systems. Oxford, UK: UNESCO Publishing.

Brose, A., Fügenschuh, A., Gausemeier, P., Vierhaus, I., \& Seliger, G. (2013). System dynamic enhancement for the scenario technique. Berlin.

Cheng, A., Pang, M., \& Pavlou, P. A. (2019). Mitigating Traffic Congestion: The Role of Intelligent Transportation Systems. The London School of Economics and Political Science. https://doi.org/10.1287/isre.2019.0894

Chowdhury, M. A., \& Sadek, A. W. (2003). Fundamentals of Intelligent Transportation Systems Planning. London: Artech House.

Desertot, M., Lecomte, S., Gransart, C., \& Delot, T. (2013). Intelligent Transportation Systems. Computer Science and Ambient Intelligence. United Kingdom: John Wiley \& Sons, Inc. https://doi.org/10.1002/9781118580974.ch13 
Frances, A. \& Ojo, T. K. (2018). Managing traffic congestion in the Accra Central Market, Ghana. Journal of Urban Management, 7, 85-96. https://doi.org/10.1016/j.jum.2018.04.002

Hale, D., \& Courage, K. (2002). Prediction of traffic-actuated phase times on arterial streets. Transportation Research Record, 1811(1), 84-91. https://doi.org/10.3141/1811-10

Harahap, E., Suryadi, A., Ridwan, Darmawan, D., \& Ceha, R. (2017). Efektifitas Load Balancing Dalam Mengatasi Kemacetan Lalu Lintas (The Effectiveness of Load Balancing in Overcoming Traffic Congestion). Jurnal Matematika, 16(2), 1-7. https://doi.org/10.29313/jmtm.v16i2.3665

Ismiyanti, D., M., \& D., S. (2012). Pencemaran Udara Akibat Emisi Gas Buang Kendaraan Bermotor (Air Pollution Due To Motor Vehicle Exhaust Emissions). Universitas Muhammadiyah Jakarta.

Japan Society of Civil Engineers. (2016). Intelligent Transport Systems (ITS) Introduction Guide. Japan.

Jarasuniene, A., \& Batarliene, N. (2013). Lithuanian road safety solutions based on intelligent transportation sytems. Transport, 28(1), 97-107. https://doi.org/10.3846/16484142.2013.782895

Shaheen, S. A., \& Finson, R. (2017). Intelligent Transportation Systems, Module in Earth Systems and Environmental Sciences. https://doi.org/10.1016/B978-0-12-409548-9.01108-8

Souza, A. M. de, Pedrosa, L. L. C., Botega, L. C., \& Villas, L. (2018). An Intelligent Transportation System for Improving Safety and Traffic Efficiency. In IEEE 87th Vehicular Technology Conference (VTC Spring) (pp. 1-7). Porto. https://doi.org/10.1109/VTCSpring.2018.8417760

Springael, J., Kunsch, P. L., \& Brans, J. P. (2002). A multicriteria-based system dynamics modeling of traffic congestion caused by urban commuters. Cejors, 10, 81-97.

Sterman, J. D. (2000). Business Dynamics, Systems Thinking and Modeling for a Complex World. McGraw-Hill Inc.

Sterman, John D. (2002). System Dynamics : Systems Thinking and Modelling for A Complex World. Cambridge. Retrieved from https://www.researchgate.net/publication/44827001_Business_Dynamics_System_Thinkin g_and_Modeling_for_a_Complex_World 
Sumadi. (2006). Kemacetan Lalu Lintas pada Ruas Jalan Veteran Kota Brebes (Traffic Congestion on the Brebes City Veterans Road Section). Universitas Diponegoro.

Sun, J., Guo, J., Wu, X., Zhu, Q., Wu, D., Xian, K., \& Zhou, X. (2019). Analyzing the Impact of Traffic Congestion Mitigation: From an Explainable Neural Network Learning Framework to Marginal Effect Analyses. Sensor (Basel), 19(10), 2254. https://doi.org/10.3390/s19102254

Suryani, E. (2011). Dynamic simulation model of demand forecasting and capacity planning. In Proceedings of the Annual Meeting of Science and Technology Studies (AMSTECS'11).

Swanson, J. (2000). The Dynamic Urban Model: Transport and Urban Development. London.

United Nation. (2017). Development of Model Intelligent Transport Systems Deployments For The Asian Highway Network.

Wegener, M. (2004). Overview of Land Use Transport Models. In Handbook of Transport Geography and Spatial Systems (Vol. 5) (pp. 127-146). Emerald Group Publishing Limited. https://doi.org/10.1108/9781615832538-009

Yao, H., \& Chen, D. (2015). A system dynamics model for urban sustainable transportation planning. In 23rd International Conference on Geoinformatics. 